Illinois State University

ISU ReD: Research and eData

Theses and Dissertations

$10-2-2017$

\title{
Desert within a city: Exploring the relationship between food security, diet, and body mass index
}

Jamey Ann Baietto

Illinois State University, jabaiet@ilstu.edu

Follow this and additional works at: https://ir.library.illinoisstate.edu/etd

Part of the Human and Clinical Nutrition Commons, and the Medicine and Health Sciences Commons

\section{Recommended Citation}

Baietto, Jamey Ann, "Desert within a city: Exploring the relationship between food security, diet, and body mass index" (2017). Theses and Dissertations. 839.

https://ir.library.illinoisstate.edu/etd/839

This Thesis is brought to you for free and open access by ISU ReD: Research and eData. It has been accepted for inclusion in Theses and Dissertations by an authorized administrator of ISU ReD: Research and eData. For more information, please contact ISUReD@ilstu.edu. 


\title{
DESERT WITHIN A CITY: EXPLORING THE RELATIONSHIP BETWEEN FOOD SECURITY, DIET, AND BODY MASS INDEX
}

\author{
Jamey A. Baietto
}

\section{Pages}

Background: Food deserts are areas of decreased access to nutritious and affordable foods. Residing within a defined food desert is thought to decrease consumption of produce, dairy, and whole grains and increase consumption of energy-dense foods as well as body mass index (BMI).

Objective: The purpose of this study was to determine the effects of the level of food security on consumption of fruits, vegetables, dairy, whole grains, high-sugar foods, high-fat foods, and BMI.

Design: A one-time, self-administered data collection packet was sent to residents of a food desert. The Dietary Screener Questionnaire was utilized to determine the average daily consumption of fruit, vegetables, dairy, whole grains, high-sugar foods, and high-fat foods. Additional questions were included to determine BMI, education level, income level, employment status, grocery shopping frequency, and vehicle accessibility.

Participants: A sample population was recruited from a food desert located in Bloomington, Illinois. Surveys were sent via the United States Postal Service to 953 residents. Inclusion criteria included: at least 18 years of age, reside within the defined food desert tract, and ability to read and understand English. Participants were of any race, ethnicity, education level, or income level. 
Results: Demographic findings revealed the sample population were predominately food secure individuals with higher education levels and medium to high incomes. Statistical analysis revealed no significant correlations between level of food security, average consumption of fruit, vegetables, dairy, whole grains, energy-dense foods, or BMI. However, significant correlations were exposed between food security and mode of transportation $(r=.277, \mathrm{p}=.017)$, grocery shopping frequency $(r=.330, \mathrm{p}=.000)$ and income $(r=-.345, \mathrm{p}=.000)$. Significant correlations were found between education level and BMI $(r=-.253, \mathrm{p}=.009)$ and education level and high fat food intake $(r=-.233, \mathrm{p}=.004)$. More significant correlations were found between food groups, revealing dietary patterns and trends.

Conclusions: Findings of this study emphasize the importance of continued research of food deserts and food security. Individualized intervention strategies have the ability to address the specific needs of food desert residents, which may vary depending on the food desert. Significant correlations were found between food security and vehicle accessibility, grocery shopping frequency, and income as well as between level of education and BMI. While food insecurity was not found to have a direct correlation to diet or BMI, its correlation to other variables suggest it could have an indirect affect.

KEYWORDS: Food Desert; Food Security; BMI 


\title{
DESERT WITHIN A CITY: EXPLORING THE RELATIONSHIP BETWEEN FOOD SECURITY, DIET, AND BODY MASS INDEX
}

\author{
JAMEY A. BAIETTO
}

A Thesis Submitted in Partial Fulfillment of the Requirements for the Degree of

\section{MASTER OF SCIENCE}

Department of Family and Consumer Sciences

\section{ILLINOIS STATE UNIVERSITY}

2018 
(C) 2018 Jamey A. Baietto 


\title{
DESERT WITHIN A CITY: EXPLORING THE RELATIONSHIP BETWEEN FOOD SECURITY, DIET, AND BODY MASS INDEX
}

\author{
JAMEY A. BAIETTO
}

COMMITTEE MEMBERS:

Julie Schumacher, Chair

Jacqueline Lanier

Tammy Harpel 


\section{ACKNOWLEDGMENTS}

Thank you to my wonderful thesis committee for your support, guidance, and patience. It has been an honor working with a group of such intelligent and dedicated women. This thesis would have been near impossible without my mom, Mary, who spent endless hours folding questionnaires, stuffing, and sealing envelopes as well as my dad, Jim, who stayed after work to make the majority of the questionnaires. Thank you to the rest of my family and friends who provided unconditional support even when I was pulling my hair out—not figuratively. Stress is a nasty thing. I am grateful for Green Top Grocery for their enthusiasm and for providing coupon incentives for participants. Thank you to A.J. for always being a few steps ahead of me, providing guidance and encouragement. Thank you for inspiring me and having the uncanny ability to put me back together when I'm hysterical and useless.

J. A. B. 


\section{CONTENTS}

Page

ACKNOWLEDGMENTS

CONTENTS

ii

TABLES

iv

CHAPTER I: DESERT WITHIN A CITY: EXPLORING THE RELATIONSHIP BETWEEN

FOOD SECURITY, DIET, AND BODY MASS INDEX 1

$\begin{array}{ll}\text { Introduction } & 1\end{array}$

$\begin{array}{ll}\text { Methodology } & 4\end{array}$

Sample Population $\quad 4$

$\begin{array}{ll}\text { Data Collection } & 4\end{array}$

Demographic Information $\quad 5$

Food Security

$\begin{array}{ll}\text { Dietary Screener Questionnaire } & 6\end{array}$

Body Mass Index $\quad 6$

$\begin{array}{ll}\text { Data Analysis } & 7\end{array}$

$\begin{array}{ll}\text { Results } & 7\end{array}$

Effects of Residing in a Food Desert on Food Security Level $\quad 8$

Mean Consumption of Food Groups $\quad 8$

Correlations Between Food Security and Consumption of Fruits, Vegetables, Dairy,

$\begin{array}{lr}\text { and Whole Grains } & 8\end{array}$

Correlations Between Food Security and Consumption of High Sugar and High Fat

Foods 
$\begin{array}{ll}\text { Discussion } & 11\end{array}$

Level of Education and Body Mass Index 12

Food Security and Vehicle Accessibility, Grocery Shopping Frequency, and Income 12

Consumption of Food Groups 13

$\begin{array}{ll}\text { Limitations } & 15\end{array}$

$\begin{array}{ll}\text { Conclusion } & 16\end{array}$

$\begin{array}{ll}\text { Future Implications } & 17\end{array}$

$\begin{array}{ll}\text { References } & 19\end{array}$

$\begin{array}{ll}\text { Tables } & 24\end{array}$

CHAPTER II: IMPLICATIONS OF FOOD DESERTS ON FOOD SECURITY, DIET, AND

$\begin{array}{lr}\text { OBESITY } & 27\end{array}$

Food Desert: Determinants and Characteristics $\quad 27$

Food Security and Fruit and Vegetable Consumption $\quad 28$

Food Security and Consumption of Energy-Dense Foods 29

Food Security and Obesity $\quad 31$

Food Assistance Programs 33

Additional Associations Between Food Insecurity and Obesity 36

$\begin{array}{ll}\text { Conclusion } & 38\end{array}$

$\begin{array}{ll}\text { Implications } & 39\end{array}$

$\begin{array}{ll}\text { References } & 40\end{array}$

APPENDIX A: QUESTIONNAIRE 


\section{TABLES}

Table

Page

1. Characteristics of Food Desert Residents

2. Daily Mean Consumption of Food Groups in Cup Equivalencies

3. Pearson's Correlation Food Security and Average Consumption of Food Groups and BMI 


\section{CHAPTER I: DESERT WITHIN A CITY: EXPLORING THE RELATIONSHIP BETWEEN}

\section{FOOD SECURITY, DIET, AND BODY MASS INDEX}

\section{Introduction}

Limited access to food does not automatically resonate as a major concern in America, the land of the fast food chains, restaurants, and super-sized grocery stores. However, there are approximately 6,529 food deserts in the United States (Wright, Donley, Gualtieri, \& Strickhouser, 2016). Food deserts are regions that feature a majority of households with low incomes, a limited number of food retailers that can provide fresh produce and healthy groceries at affordable prices, and inadequate access to transportation in order to reach food retailers (Dutko, Ver Ploeg, \& Farrigan, 2012). These factors affect a household’s food security. Food security is defined as when all members of a household have access at all times to an adequate amount of nutritious food to support a healthy and active lifestyle (Anderson, 1990). When these factors are affected, such as for those living in food deserts, households experience food insecurity. Other factors such as low levels of education, weak social networks, low income, low social capital, and being unemployed also increase the likelihood of food insecurity (Smith, Rabbitt, Coleman-Jensen, 2017).

The food, if any, readily available and affordable to individuals living in food deserts are often those low in nutrients but high in fats and sugars-also known as energy-dense foods due to their high caloric content. Diets consisting of mostly energy-dense foods provide macronutrients, but they lack micronutrients vital for healthy development and optimal health (Wrathall, 2014). Low-income individuals have been found to have a higher consumption of low-quality foods, such as energy-dense foods (Wang et al., 2014). The substantial amount of calories energy-dense foods provide contribute to obesity, while their lack of nutrients 
contributes to inadequate nourishment, causing a hunger-obesity paradox. Research has shown that in addition to availability, the lower price of fast food compared to the higher prices of fruits and vegetables plays an influential role as to why lower income individuals, such as those residing in food deserts, choose lower quality food such as energy-dense fast food (Beydoum, Powell, \& Wang, 2008; Beydoum, \& Wang, 2008). The preference to choose energy-dense foods over more nutritious foods such as fruits, vegetables, whole grains, and dairy contributes to obesity.

The USDA provides the Dietary Guidelines to promote healthy diets. It is recommended that American adults consume a minimum of $1 \frac{1 / 2}{2}$ to 2 cups of fruit and $2 \frac{1}{2}$ to 3 cups of vegetables per day (USDA, 2017a; USDA, 2017b). It is also recommended that adults eat or drink 3 cups of dairy per day and at least $1 \frac{1}{2}$ to 2 cups of whole grains per day (USDA, 2017c; USDA, 2017d). Adherence and compliance with the USDA Dietary Guidelines for Americans has been associated with lower risk of obesity (Chen, Jaenicke, \& Volpe, 2016). Research has found that living within an area with no access to a grocery store, or a food desert, is associated with consuming significantly less fruits and vegetables than individuals who do not live in a food desert (Caspi, Kawachi, Subramanian, Adamkiewicz, \& Sorensen, 2012; Gahnche \& Sahyoun, 2015). Few studies have researched the specific consumption of dairy and whole grains in food deserts, but rather investigated overall diet quality as previously discussed.

Food insecurity has a number of implications on a person's health in addition to obesity. To, Frongillo, Gallegos, and Moore (2014) found that adults who are food insecure are more likely to have Type 2 diabetes, cardiovascular diseases, hypertension, hyperlipidemia, and inflammation. Diet serves as a modifiable risk factor for these health implications (Hu et al., 
2001; Hung et al, 2004), emphasizing the importance of addressing the composition of food desert residents' diets.

While the effect of residing in a food desert on food security, consumption of fruits, vegetables, whole grains, dairy, and energy-dense foods and on BMI have been studied separately, few studies have examined all variables concurrently within the same food desert. By examining these variables simultaneously, a greater understanding of the correlations between residing in a food deserts and diet quality can be determined. Moreover, few studies have been conducted in the Midwestern region of the United States. By having a better understanding of the relationship between food security, diet, and BMI, government officials and wellness coalitions will be able to implement initiatives and policies to improve dietary intake and reduce obesity in low-income, food desert communities. Furthermore, health professionals will have a greater understanding of ideologies of poor diet quality and obesity and thus will be able to provide proper nutrition intervention and treatment strategies.

The purpose of this study was to investigate the correlations between food security, consumption of fruits, vegetables, dairy, whole grains, high-sugar foods, high-fat foods, and BMI. All participants were residents of a food desert in a Midwestern city. The United States Department of Agriculture (USDA) defines food deserts based on a variety of criteria. For the current study, a food desert was defined as either a poverty rate of $20 \%$ or more or a median family income less than $80 \%$ of the state-wide median family income with at least $33 \%$ of the population living more than one mile from the nearest grocery store (USDA, 2015). The independent variable was the participant's level of food security. The dependent variables were defined as average intake of fruits, vegetables, dairy, whole grains, high-sugar foods, and highfat foods as well as BMI. This study aimed to answer the following questions: 
1. Does decreased food security correlate to a decreased consumption of fruits, vegetables, dairy, and whole grains?

2. Does decreased food security correlate to an increased consumption of high-sugar foods and high-fat foods?

3. Does decreased food security correlate to an increase in body mass index (BMI)? This study also examined whether income, level of education, employment status, grocery shopping frequency, and access to a vehicle correlate to food security level, BMI, or consumption of fruits, vegetables, dairy, whole grains, high sugar, and high fat foods.

\section{Methodology}

\section{Sample Population}

A sample population was recruited from the food desert tract 17113001700 located in Bloomington, Illinois (USDA, 2016). The tract is defined as low income and low access measured at a half and at one mile meaning residents have no access to a grocery store within half a mile on foot or within one mile by transportation. Addresses were provided by McLean County Regional Planning Commission, and 953 residents were sent surveys via the United States Postal Service. Inclusion criteria were: at least 18 years of age, reside within the defined food desert tract, and able to read and understand English. Participants were of any race, ethnicity, education level, or income level.

\section{Data Collection}

Residents of the food desert of interest were mailed a survey. Prior to beginning the survey, an invitation letter directed subjects to read and keep the informed consent waiver through an invitation letter. An informed consent waiver was utilized since the research presented no more than minimal risk of harm to subjects and involved no procedures for which 
consent is normally required outside of research. After reading the informed consent waiver, participants indicated that they consented to the listed procedures and acknowledged that they had been informed about the purpose, procedures, possible benefits, and risks by returning the questionnaire. They also acknowledged that they voluntarily agreed to participate in the study.

A one-time, self-administered data collection packet was completed by each participant. Participants were provided a coupon incentive for Green Top Grocery, a grocery store being built in the neighborhood, but not yet open at the time of data collection. The household member most responsible for grocery shopping was asked to complete the packet. Only one packet was completed per household. Each packet included a pre-paid envelope for the participant to mail the completed packet back to the researcher.

\section{Demographic Information}

Each participant reported demographic information including income level, height, and weight. Participants were also asked to report their race, ethnicity, education level, marital status, and age. Additional information on grocery shopping frequency and how the participant gets to the grocery store was collected.

\section{Food Security}

Food security was measured by a six-item questionnaire adapted from the U.S. Household Food Security Survey Module from the USDA (Appendix A) (USDA, 2017e). Responses "Yes, Often true, Sometimes true, Almost every month, Some months but not every month, Only 1 or 2 months” were coded as affirmative. The responses “No, Never true, and Don't know” were coded as not-affirmative. The sum of the affirmative responses was the household's raw score on the scale. A raw score of 0 was defined as high food security, 1 was 
defined as marginal food security, 2-4 was defined as low food security, and 5-6 was defined as very low food security.

\section{Dietary Screener Questionnaire}

Diet quality was measured using the Dietary Screener Questionnaire (DSQ) from the National Institutes of Health (Appendix A). It has been validated as a useful tool to assess diet quality by estimating intake of fruits and vegetables, fiber, and energy of fat (Thompson, Midthune, Submar, McNeel, Berrigan, \& Kipnis, 2005). The DSQ is a 30-item questionnaire that determines the frequency of consumption of certain foods over the past month. Responses for a majority of the questions were based on a 9-point scale, while four questions were based on an 11-point scale, where intake of a specific food was inquired. Responses ranged from "Never" to "2 or more times per day" for the 9-point scale and "Never" to "6 or more times per day" for the 11-point scale. Responses were converted into daily cup equivalences. Reported monthly frequencies were divided by 30 , reported weekly frequencies were divided by 7 , and reported daily frequencies were used as reported to ensure all variables were analyzed using a common unit of time (i.e. day). Food items from the $D S Q$ were combined to create categories of food groups. Categories created included fruit, vegetables, dairy, whole grains, high-sugar foods, and high-fat foods. Average daily consumption of each food group was calculated by adding the daily cup equivalences for each food item in the category. Permission to use the DSQ was granted for usage by the National Institutes of Health.

\section{Body Mass Index}

Self-reported measurements of height and weight were used to calculate BMI. BMI was calculated as weight $(\mathrm{kg})$ divided by height squared $\left(\mathrm{m}^{2}\right)$. BMI is classified into categories. Underweight is defined as a BMI less than 18.5, normal is defined as a BMI 18.5-24.9, 
overweight is defined as a BMI 25.0-29.9, and obese is defined as a BMI 30.0 and above (Centers for Disease Control, 2015).

\section{Data Analysis}

All data were analyzed using the Statistical Package for the Social Sciences (SPSS for Windows version 21, SPSS, Inc, Chicago, IL). Descriptive statistics including means and standard deviations were conducted for participant demographics and all variables. Pearson's r correlation analysis was utilized to analyze the relationship of level of food security with average intakes of fruits, vegetables, dairy, whole grains, foods high in sugar, foods high in fat, and BMI.

To determine the association between food security and intake of the different food categories and BMI, Pearson's r Correlations were performed using the level of $\mathrm{p}<0.05$ to determine significance. In part one, the independent variable (food security score) and the dependent variables (average intakes of the different food groups and BMI) were entered with control variables. Control variables included income, grocery shopping frequency, mode of transportation (vehicle accessibility), and level of education.

\section{Results}

As previously stated, 953 surveys were mailed to residents of the food desert of interest; however, 90 surveys were returned to the researchers by the USPS due to the address being “vacant” or a “non-existing number.” Of the remaining 863 surveys, a total of 113 surveys were collected, indicating a return rate of $13 \%$. The majority of participants were white (95\%), female (70.8\%), holders of a 4-year college degree or more (56.8\%), employed full time (59.8\%), and owned their own car (87\%). Demographic characteristics for participants are displayed in Table 1. 


\section{Effects of Residing in a Food Desert on Food Security Level}

Food Security scores were calculated based on the number of affirmative responses on the six-item questionnaire. A raw score of 0 was defined as high food security, indicating the participant did not have trouble finding or affording food. A score of 1 was defined as marginal food security, 2-4 was defined as low food security, and 5-6 was defined as very low food security. Therefore, lower scores indicated food security, while higher scores indicated food insecurity. The mean food security score was found to be $1.10(\mathrm{SD}=1.85)$, indicating marginal food security. Results can be found in Table 1 .

\section{Mean Consumption of Food Groups}

The average consumption of fruit, vegetables, dairy, whole grains, high sugar foods, and high fat foods were found by converting DSQ daily cup equivalences. Daily cup equivalences were used in order to compare consumption with the USDA dietary guidelines. All food groups were found to have lower mean consumptions compared to the guidelines. Mean consumption of fruit was .44 cup $(S D=.379)$, mean vegetable consumption was 0.912 cup $(S D=.484)$, mean consumption of dairy was .548 cup $(\mathrm{SD}=.411)$, mean consumption of whole grains was .434 cup (SD = .369), mean consumption of high sugar foods was .893 cup (SD = .735), and mean consumption of high fat foods was .715 cup (SD = .484). Results can be found in Table 2 .

\section{Correlations Between Food Security and Consumption of Fruits, Vegetables, Dairy, and}

\section{Whole Grains}

Pearson's correlations did not reveal statistically significant negative correlations between food security level and consumption of fruits, vegetables, dairy, and whole grains. Data analysis revealed a minor negative correlation between food security and consumptions of fruits, however the correlation was not significant $(r=-.023, \mathrm{p}=.395)$. The results suggest that food 
security was associated with higher consumption of fruits, while food insecurity was associated with lower consumption. Food security and vegetables were also found to have a minor negative correlation, but it was not statistically significant $(r=-.025, \mathrm{p}=.793)$. Similar to the results of fruit consumption, the results suggest that food security was associated with increased consumption of vegetables, while food insecurity was associated with decreased consumption. Whole grains and dairy were both found to have minor positive relationships with food security; however, the correlations were not significant $(r=.008, \mathrm{p}=.935 ; r=.113, \mathrm{p}=.243)$. Unlike fruits and vegetables, in this sample population, food security was found to have lower consumption of whole grains and dairy, while food insecurity was associated with higher consumption of whole grains and dairy. Results can be found in Table 3.

\section{Correlations Between Food Security and Consumption of High Sugar and High Fat Foods}

Regarding food security and the consumption of high sugar and high fat foods, Pearson’s correlation did not reveal any statistically significant positive correlations. Data analysis revealed a minor positive, but insignificant, correlation between food security score and consumption of high sugar foods $(r=.040, \mathrm{p}=.680)$. Although not significant, this indicates that increased food insecurity is related to increased consumption of high sugar foods. Food security score was found to have a minor negative, but insignificant, correlation to high fat foods $(r=-.016, \mathrm{p}=.869)$. The results suggest that of the sample population, higher food security homes eat more fat than homes that experience food insecurity. Results can be found in Table 3.

\section{Correlation Between Food Security and Body Mass Index}

The mean BMI was 27.99 (SD = 6.97), indicating an overweight status. Pearson’s correlation revealed a slight positive relationship between food security score and BMI, however it was not statistically significant $(r=.009, \mathrm{p}=.929)$. The results suggest that in the sample 
population, participants who experienced greater food insecurity had higher BMIs, while those who were food secure had lower BMIs. Results can be found in Table 3.

\section{Correlations Between Variables}

Although no significant correlations were found to support the proposed research questions, significant correlations were found between variables. Significant correlations were found between food security score and income $(r=-.345, \mathrm{p}=.000)$, grocery shopping frequency $(r=.330, \mathrm{p}=.000)$, and transportation mode $(r=.017, \mathrm{p}=.000)$. The negative relationship between food security score and income suggests that food secure participants had higher incomes than food insecure participants. Food security score and grocery shopping frequency were found to have a positive relationship, indicating that food secure participants grocery shopped more frequently than food insecure participants. Similarly, food security score and transportation were found to have a positive correlation. This suggests that food secure participants were more likely to own a car than food insecure participants. Results can be found in Table 3.

Significant correlations were also found between dependent variables such as vegetable consumption and dairy consumption $(r=.207, \mathrm{p}=.033)$, whole grain consumption and fruit consumption $(r=.211, \mathrm{p}=.028)$, whole grain consumption and vegetable consumption $(r=.281$, $\mathrm{p}=.003)$, and high sugar foods consumption and high fat foods consumption $(r=.460, \mathrm{p}=$ .000). Interestingly, whole grain consumption was significantly correlated to consumption of both high sugar and high fat foods $(r=.258, \mathrm{p}=.007 ; r=.246, \mathrm{p}=.010)$. The positive correlations between the food categories indicate that higher consumption of one is associated with higher consumption of the other. The positive correlations between vegetables and dairy, whole grains and fruit, and whole grains and vegetables suggest that consumption of one food 
group that is considered to be healthy is associated with consumption of other healthy food groups, indicating a higher diet quality. Similarly, the positive correlation between food categories considered to be unhealthy (i.e. high fat and high sugar foods) indicate lower diet quality. Results can be found in Table 3.

Transportation was found to have a significantly positive correlation with grocery shopping frequency $(r=.229, \mathrm{p}=.016)$. Higher scores in mode of transportation indicated access to a vehicle. The results suggest that owning or having access to a vehicle is associated with a greater number of trips to the grocery store.

Level of education was found to have moderate negative correlations with BMI $(r=$ $.253, \mathrm{p}=.009)$ and consumption of high fat foods $(r=-.273, .004)$. The results suggest individuals with lower levels of education have higher BMIs and consume more high fat foods.

\section{Discussion}

Food security was not found to be significantly correlated with average consumption of fruit, vegetables, dairy, whole grains, high sugar food, high fat food, and BMI in the present study. However, significant correlations were found to exist between level of education and BMI; food security and mode of transportation, grocery shopping frequency, and income; and between consumption of the food categories. While food security was not found to have a direct correlation to diet or BMI, its correlation to other variables suggest it could have an indirect affect.

Demographics of food deserts are characteristically low-income, low-education, foodinsecure households that lack access to a vehicle. The demographics of the currently researched food desert did not correspond. The majority of participants were not considered low-income, had at least a 4-year college degree, were food secure, and had access to a vehicle. These 
characteristics most likely had a role in concealing any significant correlations between food insecurity, diet, and BMI.

\section{Level of Education and Body Mass Index}

The results of the current study are similar to those of Benson, von Hippel, and Lynch (2017), who found the more education an adult has, the lower the average BMI. Additionally, level of education was found to be negatively correlated with consumption of high fat foods. This indicates that implementation of education on healthy diets and lifestyle choices at younger ages may reach more individuals. Finger, Tylleskar, Lampert, and Mensink (2013) found that men and women with only a low education had higher consumption of high sugar and high fat foods as well as lower consumption of fruit and vegetables than those with a higher education. BMI is a reflection of diet and lifestyle choices; therefore, results like those of the current study

emphasize the importance of implementing education of a healthy diet and lifestyle from a young age. Those with higher educations in order to provide early intervention of obesity and comorbidities.

\section{Food Security and Vehicle Accessibility, Grocery Shopping Frequency, and Income}

Research has revealed that a lower rate of vehicle accessibility is correlated to increased food insecurity in food deserts (Dutko, Ver Ploeg, \& Farrigan, 2012; United States Department of Agriculture, 2009). Ver Ploeg, Mancino, Todd, Clay, and Scharadin (2015) found that households with fewer resources, such as those who are food insecure, are less likely to own or have access to a vehicle for grocery shopping. The current study found a significant positive correlation between food security and vehicle accessibility $(r=.277, \mathrm{p}=.017)$, indicating that food security was associated with having access to a vehicle, while food insecurity was associated with a lack of access. However, the majority of residents had access to a vehicle. 
The current study revealed that food insecurity was correlated to lower household income. The results support those of Bukenya (2017) who found a negative relationship between household income and food insecurity. It was found that food insecurity decreased by a factor of $12.4 \%$ as income increased by one level, indicating that households with higher incomes were less likely to experience food insecurity (Bukenya, 2017). The results of both studies are expected. Households with higher incomes have more resources to purchase adequate amounts of food to support healthy and active lifestyles.

\section{Consumption of Food Groups}

As previously discussed, the USDA provides the Dietary Guidelines for Americans to promote healthy diets. The USDA recommends that American adults consume a minimum of 1 $1 / 2$ to 2 cups of fruit and $2 \frac{1}{2} 2$ to 3 cups of vegetables per day (USDA, 2017a; USDA, 2017b). The results of the current study revealed mean consumptions of fruit and vegetables that did not meet these recommendations. Average fruit consumption was under half of a cup $(\mathrm{m}=.443, \mathrm{SD}=$ $.379)$, while average vegetable consumption was under 1 cup $(\mathrm{m}=.912$, $\mathrm{SD}=.484)$. These results are not surprising, as literature shows that residents of food deserts do not consume adequate amounts of fruits and vegetables. Comparable results were found by Gahche and Sahyoun (2015), who found that high income individuals not living in a food desert consumed 0.24 more cup equivalents of vegetables on any day compared to low income individuals living in a food desert (Gahnche \& Sahyoun, 2015). Additionally, the same study found that low income individuals not living in a food desert consumed 0.21 more cups of vegetables than low income individuals living in a food desert (Gahnche \& Sahyoun, 2015). The results revealed that regardless of income level, food desert residents consumed less vegetables compared to those not residing in a food desert. The USDA recommends adults eat or drink 3 cups of dairy per day and 
at least $1 \frac{1 / 2}{2}$ to 2 cups of whole grains per day (USDA, 2017c; USDA, 2017d). Much like the consumption of fruits and vegetables, the consumption of dairy and whole grains were found to be below the USDA recommendations $(\mathrm{m}=.548, \mathrm{SD}=.411 ; \mathrm{m}=.434, \mathrm{SD}=.369)$. The low consumption compared to recommendations could be attributed to reduced accessibility of fresh produce and healthy groceries.

Decreased consumption of fruits, vegetables, dairy, and whole grains in food deserts are not uncommon. Kirkpatrick, Dodd, Reedy, and Krebs-Smith (2012) found that individuals in households in the lowest middle-income groups had suboptimal consumption of whole fruits, vegetables, whole grains, and milk. Cost also plays a noteworthy role as to why consumption of healthier food groups suffers in food deserts (Beydoum, \& Wang, 2008; Beydoum, Powell, \& Wang, 2008). Farmers markets and community gardens are options to increase the amount of affordable produce available in food deserts. One study found that participation in a community garden was significantly and positively associated with meeting daily fruit and vegetable recommendations (Barnidge, Hipp, Estlund, Duggan, Barnhart, \& Brownson, 2013). Programs likes these provide fresh produce directly to communities for reduced or no price, addressing the issues of affordability and accessibility.

Nevertheless, the demographics of the studied food desert must remain in consideration. The majority of participants were found to have medium- to high-incomes, at least a 4-year college degree, access to a vehicle, and were food secure. Therefore, the consumption patterns are difficult to compare to those of existing food insecure literature. It could be assumed that residents had the means to access and afford appropriate amounts of food, but simply chose highsugar and high-fat foods, as found in the results. This indicates that accessibility may not play as 
pertinent of a role in diet as previously thought. Personal preference and knowledge of nutrition may have a greater influence.

\section{Limitations}

It is important to consider limitations of the current study when interpreting the results. Of the 953 residents identified by the McLean County Regional Planning Commission of the area who were sent surveys, only 113 responded, leaving a majority of the population unrepresented. Results revealed that $84.9 \%$ of participants had an income level greater than $\$ 20,000$ and that $85 \%$ owned their own vehicle. These are not characteristically seen in food deserts. The mean food security score was found to be $1.10(\mathrm{SD}=1.85)$, indicating moderate level of food security. As previously discussed, food deserts typically present as low-income, food insecure neighborhoods (Dutko, Ver Ploeg, \& Farrigan, 2012). No existing published literature to the researchers' knowledge assessed the level of food security within a food desert as evaluated in the current study. The present results suggest that future studies should assess

food security in order to acquire a greater understanding of food access for all residents in a food desert.

The current study used mailed survey packets to collect data; however, greater participation might have been achieved if more specific recruiting and a more convenient mode of collecting data were utilized such as online surveys. Additionally, food frequency questionnaires were utilized to calculate average consumption of food items due to userfriendliness. More accurate results might have been found with the use of more specific food recalls such as a 24-hour recall or food diary. Both methods require more time and resources from the researchers and the participant and is consequently why food frequency questionnaires were used in this study. 


\section{Conclusion}

Findings of this study emphasized the importance of continued research of food deserts and food security. Decreased food security was not found to be significantly correlated to a decreased consumption of fruits, vegetables, dairy, or whole grains nor was it found to be correlated to an increased consumption of high sugar or high fat foods or and increased BMI. The participants were atypical in terms of what is characteristically seen in food deserts. Most importantly, a majority of participant were not found to be food insecure. Therefore, the results cannot be generalized to all food deserts who residents are typically food insecure.

Significant correlations were found between food security and vehicle accessibility, grocery shopping frequency, and income as well as between level of education and BMI. Although food security was not found to have a significantly direct role in diet in the present study, its correlation to vehicle accessibility and grocery shopping frequency suggest an indirect role.

The current study fills the gap in the literature regarding the roles food security level, vehicle accessibility, income, and level of education play in food deserts. It also reveals consumption patterns in food secure versus food insecure households. However, the results should not be generalized to all food deserts due to its demographics being uncharacteristic to those of classic food deserts. The results can be utilized by local government and wellness coalitions to address the area in need. Although national programs, attention, and funding are optimal, it is not always feasible. Community efforts such as farmers' markets and community gardens may be helpful solutions to increase accessibility and consumption of nutritious foods. The current study provides specific data on the residents of the food desert studied. Similar methods can be utilized in other food deserts to assess the best type of assistance for that specific 
food desert. Updated data would provide a more relevant and accurate outlook on the current statuses of food deserts across the United States.

\section{Future Implications}

In order to address the needs of food desert residents, officials must increase their understanding of the implications of residing in a food desert. By further studying and researching food deserts, more associations and factors can be identified. This can lead to the development of intervention and prevention strategies that can be implemented to address diet composition and decrease the prevalence of obesity. These would most likely include education on healthy lifestyle behaviors and basic nutrition as well as other previously discussed strategies.

The food desert tract of interest in this study can no longer be researched as a food desert as the co-op Green Top Grocery opened in May of 2017. Future research can be conducted to see if the opening of a grocery store in a food desert improves diet quality, BMI, and food security level. Current research has not found significant evidence that the opening of grocery stores in food deserts improves diet composition or BMI (Dubowitz et al, 2013; Dubowitz et al., 2015; Wright, Donley, Gualtieri, \& Strickerhouser, 2016). However, when studying the relationship between food environment and fruit and vegetable consumption, past research found that neighborhoods with a store that sold fresh produce were associated with an increase of 0.35 daily servings of fruits and vegetables (Zenk, et al., 2012). Similarly, the presence of a large grocery store was associated with 0.69 increase of daily servings of fruit and vegetables (Zenk, et. al., 2012). These results indicate that accessibility to fresh produce can impact the quality of diet consumed by those residing in food deserts.

Future studies may also further research the findings to increase the understanding of the relationships between food security and income, level of education, and BMI. It is widely 
recognized that more research is necessary to further establish if interventions in food deserts impact diet composition, obesity prevalence, and other health outcomes (Cummins, Flint, \& Matthews, 2014; Dubowitz et al., 2013; Howlett, Davis, \& Burton, 2016). Continued research into these topics within low-income, food insecure communities has the potential to strengthen the literature and improve understanding so that government officials and wellness coalitions can implement initiatives and policies to improve dietary intake and reduce obesity. Similarly, a greater understanding of ideologies of poor diet quality and obesity could be achieved so that health professionals can implement more effective preventative, intervention, and treatment strategies. 


\section{References}

Anderson, S. E. (1990). Core indicators of nutritional state for difficult-to-sample populations. Journal of Nutrition, 120, 1559-1599. Retrieved from https://www.ncbi.nlm.nih.gov/pubmed/2243305

Barnidge, E. K., Hipp, P. R., Estlund, A., Duggan, K., Barnhart, K. J., Brownson, R. C. (2013). Association between community garden participation and fruit and vegetable consumption in rural Missouri. International Journal of Behavioral Nutrition and Physical Activity, 10, 128. doi: 10.1186/1479-5868-10-128

Benson, R., von Hoppel, P. T., \& Lynch, J. L. (2017). Short communication: Does more education cause lower BMI, or do lower-BMI individuals become more educated? Evidence from the National Longitudinal Survey of Youth 1979. Social Science \& Medicine, doi: 10.1016/j.socscimed.2017.03.042

Beydoum, M. A., \& Wang, Y. (2008). How do socio-economic status, perceived economic barriers and nutritional benefits affect quality of dietary intake among US adults? European Journal of Clinical Nutrition, 62(3), 303-313. doi: 10.1038/sj.jcn.160270

Beydoum, M. A., Powell, L. M., \& Wang, Y. (2008). The association of fast food, fruit and vegetable prices with dietary intakes among US adults: Is there modification by family income? Social Science Medicine, 66(11), 2218-2229.

Bukenya, J. (2017). Determinants of food insecurity in Huntsville, Alabama, metropolitan area. Journal of Food Distribution Research, 48(1), 73-80. 
Caspi, C. E., Kawachi, I., Subramanian, S. V., Adamkiewicz, G., \& Sorensen, G. (2012). The relationship between diet and perceived and objective access to supermarkets among lowincome housing residents. Social Science Medicine, 75(7), 1254-1262. doi:

10.1016/j.socscimed.2012.05.014

Centers for Disease Control (2015, May 15). About adult BMI. Retrieved from https://www.cdc.gov/healthyweight/assessing/bmi/adult_bmi/index.html

Chen, D., Jaenicke, E. C., \& Volpe, R. J. (2016). Food environments and obesity: Household diet expenditure versus food deserts. American Journal of Public Health, 106(5), 881-888. doi 10.21 05/AJPH.201630 3048

Cummins, S., Flint, E., \& Matthews, S. A. (2014). New neighborhood grocery store increased awareness of food access but did not alter dietary habits or obesity. Health Affairs, 33(2), 283-291. doi: 10.1377/hlthaff.2013.0512

Dubowitz, T., Ghosh-Dastidar, M. B., Steiner, E., Escarce, J. J., \& Collins, R. L. (2013). Are our actions aligned with our evidence? The skinny on changing the landscape of obesity. Obesity, 21(3), 419-420. doi: 10.1002/oby.20294

Dubowitz, T., Steiner, E. D., Hunter, G. P, Sloan, J. C., Ghosh-Dastidar, M., Cohen, D. A., Beckman, R., Florez, K. R., Huang, C., Vaughan, C. A., Collins, R. L., Zenk, S. N., \& Cummins, S. (2015). Diet and perceptions change with supermarket introduction in a food desert, but not because of supermarket use. Health Affairs, 34(11), 1858-1868. doi: 10.1377/hlthaff.2015.0667

Dutko, P., Ver Ploeg, M., \& Farrigan, T. (2012). Characteristics and influential factors of food deserts. U.S. Department of Agriculture, Economic Research Service, ERR-140. Retrieved from www.ers.usda.gov/publications/err-economic-research-report/err140.aspx 
Finger, J. D., Tylleskar, T., Lampert, T., \& Mensink G. B. M. (2013). Dietary behavior and socioeconomic position: The role of physical activity patterns. PLoS ONE, 8(11). Retrieved from https://doi.org/10.1371/journal.pone.0078390

Gahche, J., \& Sahyoun, N. (2015) Associations between vegetable-and-fruit consumption and food deserts: Urban adults 40+ years, NHANES 2003-2010. The FASEB Journal, 29(1).

Howlett, E., Davis, C., \& Burton, S. (2016). From food desert to food oasis: The potential influence of food retailers on childhood obesity rates. Journal of Business Ethics, 13(9), 215-224. DOI: 10.1007/s10551-015-2605-5

Hu, F. B., Manson, J. E., Stampfer, M. J., Colditz, G., Lui, S., Solomon, C. G., \& Willett, W. C. (2001). Diet, lifestyle, and the risk of type 2 diabetes mellitus in women. The New England Journal of Medicine, 345, 790-797. DOI: 10.1056/NEJMoa010492

Hung, H.-C., Joshipura, K. J., Jiang, R., Hu, F. B., Hunter, D., Smith-Warner, S. A., Colditz, G. A., Rosner, B., Spriegelman, D, \& Willett, W. C. (2004). Fruit and vegetable intake and risk of major chronic disease. Journal of the National Cancer Institute, 96(21), 15771584. DOI: $10.1093 /$ jhcu.djh296

Kirkpatrick, S. I., Dodd, K. W., Reedy, J., \& Krebs-Smith, S. M. (2012). Income and race/ethnicity are associated with adherence to food-based dietary guidance among U.S. adults and children. The Journal of the Academy of Nutrition and Dietetics, 112(5), 624635. doi: 10.1016/j.jand.2011.11.012

Smith, M. D., Rabbitt, M. P., \& Coleman-Jensen, A. (2017). Who are the world's food insecure? New evidence from the Food and Agriculture Organization’s Food Insecurity Experience Scale. World Development, 93,402-412. Retrieved from https://doi.org/10.1016/j.worlddev.2017.01.006 
Thompson, F. E., Midthune, D., Subar, A. F., McNeel, T., Berrigan, D., \& Kipnis, V. (2005). Dietary intake estimates in the National Health Interview Survey, 2000: Methodology, results, and interpretation. Journal of the American Dietetic Association, 105(3), 352363. doi: 10.1016/j.jada.2004.12.032

To, Q.G., Frongillo, E.A., Gallegos, D., \& Moore, J.B. (2014). Household food insecurity is associated with less physical activity among children and adults in the US population.

United States Department of Agriculture (2009). Access to affordable and nutritious food: Measuring and understanding food deserts and their consequences. Retrieved from http://www.ers.usda.gov/media/242675/ap036_1_.pdf

USDA. (2015, March 11). Retrieved from http://www.ers.usda.gov/data-products/food-accessresearch-atlas/documentation.aspx

USDA. (2016, November 17). Food access research atlas. Retrieved from https://www.ers.usda.gov/data-products/food-access-research-atlas/go-to-the-atlas/

USDA (2017a, April 5). All about the fruit group. Retrieved from https://www.choosemyplate.gov/fruit

USDA (2017b, April 5). All about the vegetable group. Retrieved from https://www.choosemyplate.gov/vegetables

USDA (2017c, April 5). All about the dairy group. Retrieved from https://www.choosemyplate.gov/dairy

USDA (2017d, April 5). All about the grains group. Retrieved from https://www.choosemyplate.gov/grains

USDA (2017e, October 4). Survey tools. Retrieved from https://www.ers.usda.gov/topics/foodnutrition-assistance/food-security-in-the-us/survey-tools/\#six 
Ver Ploeg, M., Mancino, L, Todd, J. E., Clay, D. M., Scharadin, B. (2015). Where do Americans usually shop for food and how do they travel to get there?: Initial findings from the National Household Food Acquisition and Purchase survey. United States Department of Agriculture, Economic Research Service. Retrieved from http://www.rootcausecoalition.org/wp-content/uploads/2016/03/eib138.pdf

Wang, D. D., Leung, C. W., Li, Y., Ding, E. L., Chiuve, S. E., Hu, F. B., \& Willett, W. C. (2014). Trends in dietary quality among adults in the United States, 1999 through 2010. JAMA Internal Medicine, 174(10), 1587-1595. doi: 10.1001/jamainternmed.2014.3422

Wrathall, J. (2014). Linking obesity and malnutrition. International Journal of Sociology, 44(2), 63-86. doi: 10.2753/IJS0020-7659440203

Wright, J. D., Donley, A. M., Gualtieri, M. C., \& Strickhouser, S. M. (2016). Food deserts: What is the problem? What is the solution? Society, 53(1) DOI: 10.1007/s12115-016-9993-8

Zenk, S. N., Schulz, A. J., Kannan, S., Lachance, L. L., Mentz, G., Ridella, W. (2012). Neighborhood retail food environment and fruit and vegetable intake in a multiethnic urban population. The American Journal of Health Promotion, 23(4), 255-264. doi: 10.4278/ajhp.071204127. 


\section{Tables}

Table 1

Characteristics of Food Desert Residents

\begin{tabular}{|c|c|c|}
\hline $\begin{array}{l}\text { Measure } \\
(n=113)\end{array}$ & $M$ & $S D$ \\
\hline Age (years) & 50 & 16.516 \\
\hline BMI & 28 & 7.0418 \\
\hline \multirow[t]{2}{*}{ Food Security Score } & 1.10 & 1.85 \\
\hline & Frequency & $\underline{\text { Percent }}$ \\
\hline \multicolumn{3}{|l|}{ Sex } \\
\hline Male & 33 & 29.2 \\
\hline Female & 80 & 70.8 \\
\hline \multicolumn{3}{|l|}{ Ethnicity } \\
\hline Black or African American & 1 & .9 \\
\hline White & 104 & 92 \\
\hline Other & 4 & 3.5 \\
\hline \multicolumn{3}{|l|}{ Education Level } \\
\hline \multirow{2}{*}{ Received high school diploma or GED } & 17 & 15.0 \\
\hline & 31 & 27.4 \\
\hline 4-year degree or more & 63 & 55.8 \\
\hline \multicolumn{3}{|l|}{ Employment Status } \\
\hline Not employed & 6 & 5.3 \\
\hline Employed part time & 9 & 8.0 \\
\hline Employed full time & 67 & 59.3 \\
\hline Other & 27 & 23.9 \\
\hline \multicolumn{3}{|l|}{ Marital Status } \\
\hline Married & 46 & 40.7 \\
\hline Living with partner & 14 & 12.4 \\
\hline Separated/divorced & 25 & 22.1 \\
\hline Single, never married & 19 & 16.8 \\
\hline Other & 8 & 7.1 \\
\hline \multicolumn{3}{|l|}{ Income Level } \\
\hline Less than $\$ 20,000$ & 12 & 10.6 \\
\hline$\$ 20,000-\$ 39,999$ & 26 & 23.0 \\
\hline$\$ 40,000-\$ 59,999$ & 26 & 23.0 \\
\hline$\$ 60,000-\$ 79,999$ & 20 & 17.7 \\
\hline$\$ 80,000$ or higher & 24 & 21.2 \\
\hline Mode Transportation to Grocery Store & & \\
\hline On bike or on foot & 3 & 2.7 \\
\hline A car I own & 96 & 85.0 \\
\hline Public Transportation & 5 & 4.4 \\
\hline Other & 6 & 5.3 \\
\hline Grocery Shopping Frequency & & \\
\hline More than once a week & 24 & 21.2 \\
\hline Once a week & 54 & 47.8 \\
\hline Once every 2 weeks & 30 & 26.5 \\
\hline Once a month or less & 4 & 3.5 \\
\hline I don’t know & 1 & .9 \\
\hline
\end{tabular}


Table 2

Daily Mean Consumption of Food Groups in Cup Equivalencies

\begin{tabular}{|c|c|c|c|}
\hline Measure & $M$ & $S D$ & Range \\
\hline Average Fruit & .443 & .379 & 2.29 \\
\hline Consumption & & & \\
\hline $\begin{array}{l}\text { Average Vegetable } \\
\text { Consumption }\end{array}$ & .912 & .484 & 2.33 \\
\hline $\begin{array}{l}\text { Average Dairy } \\
\text { Consumption }\end{array}$ & .548 & .411 & 1.57 \\
\hline $\begin{array}{l}\text { Average Whole Grains } \\
\text { Consumption }\end{array}$ & .434 & .369 & 1.66 \\
\hline $\begin{array}{l}\text { Average High Sugar } \\
\text { Foods Consumption }\end{array}$ & .893 & .735 & 3.75 \\
\hline $\begin{array}{l}\text { Average High Fat Food } \\
\text { Consumption }\end{array}$ & .715 & .484 & 1.74 \\
\hline
\end{tabular}




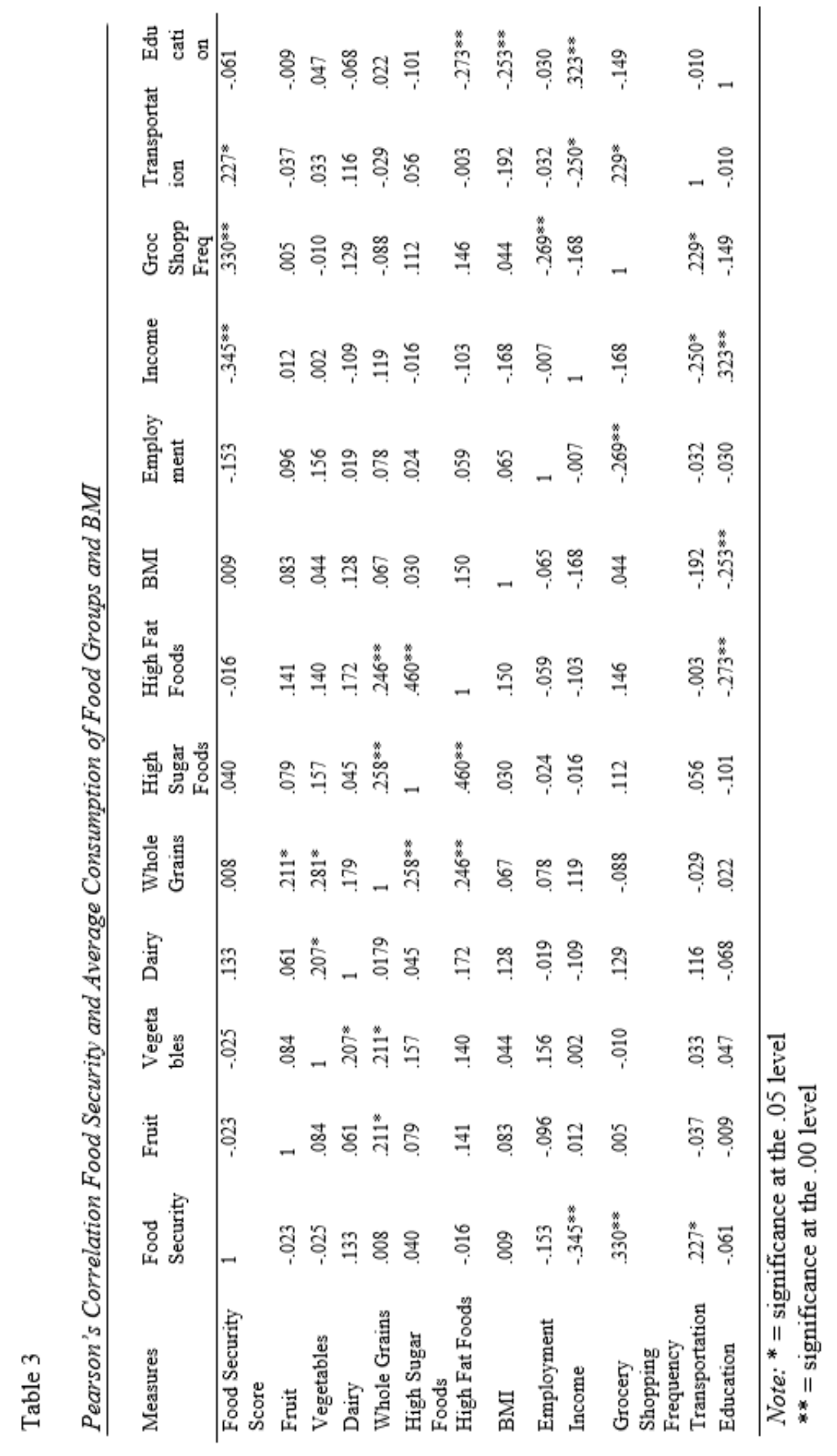




\section{CHAPTER II: IMPLICATIONS OF FOOD DESERTS ON FOOD SECURITY, DIET, AND}

\section{OBESITY}

\section{Food Desert: Determinants and Characteristics}

There are approximately 6,529 food deserts in the United States (Wright, Donley, Gualtieri, \& Strickhouser, 2016). Food deserts are regions that feature a majority of households with low incomes, a limited number of food retailers that can provide fresh produce and healthy groceries at affordable prices, and inadequate access to transportation in order to reach food retailers (Dutko, Ver Ploeg, \& Farrigan, 2012). These areas typically lack access to healthy foods but have access to less nutritious foods, which ultimately increases the risk of obesity and dietrelated diseases (United States Department of Agriculture, 2009).

In 2015, the Economic Research Service (ERS) of the United States Department of Agriculture (USDA) found that $12.7 \%$ of American households were food insecure (ColemanJensen, Rabbitt, Gregory, \& Sighn, 2016). Prevalence of food insecurity varies depending on the demographic and economic characteristics of a household. The same study found that food insecurity rates were higher than the national average for households with children, households headed by a single parent, women and men living alone, households headed by Black, nonHispanics and Hispanics, and low-income households with incomes below 185\% of the poverty threshold (Coleman-Jensen et. al., 2016).

McEntee and Agyman (2009) describe three types of food insecurity experienced which include informational, economic, and geographic. Informational access encompasses factors that relate to the educational, cultural, and social constraints that influence how and why people choose to eat certain foods (McEntee \& Agyman, 2009). Research examining the association between food insecurity and level of education completed has found that households who have 
completed a high school diploma or less tend to be food insecure (Rose, 1999). Additionally, counties considered food deserts typically have a larger proportion of individuals without a high school diploma (Morton \& Blanchard, 2007). Economic access involves how poverty, food prices, and transportation costs affect one’s ability to acquire food (McEntee \& Agyeman, 2009). Hendrickson, Smith, and Eikenberry (2006) discovered that areas with high poverty experienced higher food costs and lower food quality. Geographic access refers to physical distance from sources of food (McEntee \& Agyeman, 2009). It is well established that urban residents experience inadequate access if they live more than five-hundred meters from a food retailer (Clarke et. al., 2002; Guy \& David, 2004; Whelan et. al, 2002; Wrigley et. al., 2002); thus, living beyond this set distance is considered to be living in a food desert (McEntee \& Agyeman, 2009). Living beyond this distance makes attaining adequate nutrition difficult, which in turn coincides with a decreased consumption of nutritious foods.

\section{Food Security and Fruit and Vegetable Consumption}

The USDA recommends that American adults consume a minimum of $1 \frac{1 / 2}{2}$ to 3 servings of fruit and $2 \frac{1}{2}$ to 4 servings of vegetables per day (USDA, 2016). However, these recommendations are rarely met in food deserts, which, as previously discussed, consist of low income and higher poverty households. Grimm, Foltz, Blanck, and Scanlon (2012) assessed the relationship between poverty income ratio (PIR) and fruit and vegetable consumption. It was revealed that only $21.3 \%$ of adults living at greatest poverty were consuming vegetables at least three times a day (Grimm et. al., 2012). Similarly, the percent of adults consuming at least two vegetables per day was lower in adults living at greatest poverty when compared to those living at least poverty (Grimm et. al., 2012). 
Gahche and Sahyoun (2015) studied the association of fruit and vegetable consumption and food deserts using data from the 2003 to 2010 National Health and Nutrition Examination Survey (NHANES) and the USDA's food desert locator database. Findings reported high income individuals not living in a food desert consumed 0.24 more cup equivalents of vegetables on any day compared to low income individuals living in a food desert (Gahnche \& Sahyoun, 2015). Additionally, low income individuals not living in a food desert consumed 0.21 more cups than low income individuals living in a food desert (Gahnche \& Sahyoun, 2015). Although both groups of low income individuals consumed less vegetables than high income individuals, the higher consumption of vegetables in low income individuals who do not live in a food desert compared to those who do indicate that living in a food desert has a greater impact on vegetable consumption. This is most likely due to the lack of fresh produce available in food deserts.

In studying the relationship between food environment and fruit and vegetable consumption, it was found that neighborhoods with a convenience store were associated with 1.84 fewer daily servings of fruit and vegetables (Zenk, Schulz, Kannan, Lachance, Mentz, \& Ridella, 2012). Contrarily, neighborhoods with a store that sold fresh produce were associated with an increase of 0.35 daily servings of fruits and vegetables (Zenk, et al., 2012). Similarly, the presence of a large grocery store was associated with 0.69 increase of daily servings of fruit and vegetables (Zenk, et. al., 2012). These results indicate that accessibility to fresh produce can impact the quality of diet consumed by those residing in food deserts.

\section{Food Security and Consumption of Energy-Dense Foods}

A diet rich in nutritious foods such as fruits, vegetables, whole grains, and nuts is linked to reduced risk of obesity which correlates to a decrease in the plethora of health implications associated with obesity (Wrathall, 2014). However, as discussed previously, a low-quality diet 
that is high in saturated fat, trans fat, or refined sugars is linked to increased risk of obesity and health implications such as diabetes and cardiovascular disease (United States Department of Agriculture, 2009).

Energy-dense foods that lack nutrition are more likely to be cheap and convenient. Drewnoski and Specter (2004) explained that developments in agriculture and food technology have made energy-dense foods easily accessible at low costs and have a long shelf life. Low income individuals are more likely to buy and consume these types of food due to these very reasons. Surveys from the United States Department of Agriculture (USDA) revealed that most low-income respondents spend their food dollars on energy-dense foods (Drewnoski \& Specter, 2004). Low-income individuals purchase and consume foods that contain high amounts of fats, sugar, and refined carbohydrates because they are more readily available and cheap when faced with such conditions as a food desert.

Alviola, Nayga, Thomsen, and Wang (2013) examined the food environments of lowincome and rural communities in Arkansas over a period from 2004 to 2010. Major findings included individuals living in food deserts have more exposure to fast-food restaurants and convenience stores. This indicates that living in a food desert leads to disadvantages in diet due to greater access to unhealthy foods and less access to healthy foods (Alviola, Nayga, Thomsen, \& Wang, 2013).

Similarly, Kirkpatrick, Dodd, Reedy, and Krebs-Smith (2012) found that individuals in households in the lowest middle-income groups had suboptimal consumption of whole fruits, vegetables, whole grains, and milk. Research has shown that the higher prices of fruits and vegetables compared to the price of fast food plays an influential role as to why lower income 
individuals choose fast, lower quality, food (Beydoum, \& Wang, 2008; Beydoum, Powell, \& Wang, 2008). Diets consisting of low quality, fast food may lead to increased obesity.

The foods readily available and affordable to individuals living in food deserts are those that are low in nutrients, but high in fats and sugars—also known as energy-dense foods due to their high calorie content. Wrathall (2014) explained, “obesity can be comorbid with malnutrition. Poor diets may provide basic macronutrients—-protein, fats, and carbohydrates— but lack micronutrients such as folic acid required for healthy development. A person may be overweight but malnourished from eating large quantities of bulk energy deficient in essential nutrients” (p. 67). So, while low income individuals may be consuming an adequate—or an overabundant—number of calories, the foods they are consuming lack vital nutrients to keep them nourished.

\section{Food Security and Obesity}

Food insecurity has many implications on a person’s health. To, Frongillo, Gallegos, and Moore (2014) uncovered that adults who are food insecure are more likely to have Type 2 diabetes, cardiovascular disease, hypertension, hyperlipidemia, and inflammation. These health implications are related to obesity caused by poor diet choices. Poor diets that consist of energydense foods that lack nutrition are more likely to be cheap and convenient. Drewnoski and Specter (2004) explained that developments in agriculture and food technology have made energy-dense foods easily accessible at low costs and have a long shelf life. Low income individuals are more likely to buy and consume these types of food due to these very reasons. Surveys from the United States Department of Agriculture (USDA) demonstrated that most lowincome respondents spend their food dollars on energy-dense foods (Drewnoski \& Specter, 2004). Low-income individuals purchase and consume foods that contain high amounts of fats, 
sugar, and refined carbohydrates because they are more readily available and cheap when faced with such conditions as a food desert. However, these foods can lead to an increased BMI.

Chen, Jaenicke, and Volpe (2016) examined the associations between obesity and multiple aspects of food environments of homes and neighborhoods. Data was collected from 38,650 individuals within 18,3281 households located in 2104 counties of the United States. Obesity and overweight status were determined by calculating BMI. Household level demographic characteristics inferred included race/ethnicity, house hold size, income, education, and marital status. Neighborhood-level variables included the average number of food stores or restaurants per 10,000 county residents, county-level poverty rates, and food desert status. The major findings exposed that when other factors were held constant, residing in a food desert increased an individual's odds of being obese by $30 \%$ and of being overweight by $19 \%$ (Chen, Jaenicke, \& Volpe, 2016).

Similarly, Kaur, Lamb, and Ogden (2015) examined the association between food insecurity and obesity in children. The study was conducted using five National Health and Nutrition Examination Surveys (NHANES) from 2001 to 2010. The data consisted of 12,306 participants whose obesity status was determined if their BMI was greater or equal to age and sex-specific $95^{\text {th }}$ percentile of the 2000 Centers for Disease Control and Prevention growth charts. Conclusion of the study found that obesity was significantly associated with food insecurity for children aged six to eleven years old (Kaur, Lamb, \& Ogden, 2015). While such findings add to the literature establishing the relationship between food deserts and obesity, it is unclear whether proximity of grocery stores with healthy food options or proximity of sources for unhealthy foods such as fast food restaurants play a more significant role. 
Chen, Florax, and Snyder (2009) examined the relationship between proximity to fast food restaurants and grocery stores and BMI. Major findings of this study found that proximity to fast food restaurants had a small positive impact on BMI, while proximity to a grocery store has a small negative impact on BMI (Chen, Florax, \& Snyder, 2009). In other words, the distance one resides from a grocery story can negatively affect their BMI more than the distance from a fast food restaurant. As previously discussed, food deserts are more likely to be of closer proximity to fast food restaurants rather than grocery stores - both factors of which can lead to increased BMI.

The implications of food insecurity expand beyond not being able to access or afford nutritious food. Food insecurity may also affect health outcomes by causing changes in metabolism and behavior. These changes can include overeating when food is available as well as overall stress and anxiety. The stress of low income and food insecurity may lead many individuals and families to turn to food assistance programs.

\section{Food Assistance Programs}

America is not typically thought of as having a lack of food; nevertheless, millions of Americans are food insecure and are in need of food assistance. The USDA combats food insecurity through the use of three programs: Supplemental Nutrition Assistance Program (SNAP), the National School Lunch Program (NSLP), and the Special Supplemental Nutrition Program for Women, Infants, and Children (WIC). The goals of these programs are to encourage participants to adhere to the Dietary Guidelines for Americans (Hou, 2013). Although this is the goal, it is not always the reality. While the NSLP and WIC have implemented changes to increase nutrition, SNAP does not set regulations on what foods can and cannot be purchased. 
According to Leung, Ding, Catalano, Villamor, Rimm and Willett (2012), the Food Stamp Program (FSP) changed to SNAP in 2008 in order to reduce stigma and in attempt to focus more on nutrition; however, SNAP has not undergone any restructuring to provide its participants with nutrient-rich foods, restrict the purchase of nutrient-poor foods, or strengthen its nutrition education program. Research of SNAP participants have shown a consume amounts that met or exceeded recommended limits for processed meats, sweets and bakery desserts, and sugar-sweetened beverages—all behaviors that have negative health implications. The number of SNAP participants in 2011 was 44.7 million Americans; therefore, a great amount of Americans are becoming overweight and obese (Leung, et al, 2012). With so many participants, a significant amount of money is needed in order to feed these individuals. As Chen, Yen, and Eastwood (2005) exposed, the budget for SNAP (known as FSP at the time) in the fiscal year of 2004 made up around 60\% of the USDA's food assistance budget. With so much fiscal investment and so many participants in SNAP, it is vital that the outcomes are evaluated, not only for economical purposes, but for the health of the millions of participants.

The Food Stamp Act was passed in 1964 in order to increase food consumption in impoverished Americans (Baum, 2011). It was intended to act as a safety net that would prevent starvation. Wilde (2013) explained the most common way to become eligible for SNAP eligibility is to meet gross and net income limits. The monthly gross income limit is $130 \%$ of the federal poverty standard, or for a family of four, $\$ 2,422$ in 2011. The monthly net income limit is $100 \%$ of the federal poverty standard, or, for a family of four, \$1,863 in 2011.

Recipients of SNAP receive benefits once per month. Fan (2010) found that many recipients overeat when they first receive benefits, sometimes consuming up to twice the Recommended Daily Allowance (RDA). This leads to them having to restrict later in the month 
when they are running low or are running out of benefits. Fan (2010) found that FSP participants that shopped only once a month reduced their energy intake by $11.6 \%$ by the fourth week when compared to their intake during the initial week. When an individual experiences feast and famine, the body adapts by lowering the metabolism and reserving calories as fat during a feast so that it can survive during a famine (Fan, 2010). This cycle leads to weight gain, and ultimately, obesity.

Since the Food Stamp Act was passed, the prevalence of obesity has had a dramatic increase. Between 1971 and 1974, the FSP aided between 9.2 and 12.8 million participants and the prevalence of obesity in participants was 14.5\% (Baum, 2011). In 2005, the FSP aided 25.7 million and the obesity prevalence in participants was around 30\% (Baum, 2011). These figures show an increase in the percentage participant obesity. However, the increase in obesity may only be due to the increase in participants. This led many to research the relationship between SNAP and participants' likelihood of being obese. Interestingly, a number of research studies have found female participants of SNAP were associated with higher BMIs, but no significant associations have been found in male SNAP participants (Baum, 2011; Chen, Yen, \& Eastwood, 2005; Drewnowski \& Specter, 2004; Meyerhoefer \& Pylypchuk, 2008).Baum (2010) hypothesized that the connection between female obesity and SNAP participation is explained by the fact that females are more likely to be long-term recipients than males. Over $50 \%$ of incomeeligible female recipients received food stamps long-term. His research showed that receiving food stamps long-term increases obesity by almost 5.0 percentage points. Therefore, if males are only receiving short-term assistance, their BMIs are less likely to be affected (Baum, 2011). 


\section{Additional Associations Between Food Insecurity and Obesity}

SNAP participation is not the only contributing factor to why low-income, food-insecure individuals have a greater prevalence of obesity. Chatterjee, Blakely, and Barton (2005) conducted qualitative interviews with workers and participants of a community center that was located in a predominately Mexican American and low-income community. The researchers found that overeating due to family customs, high consumption of fast food, and limited physical activities were all factors that increased the community's prevalence of obesity. Many interviewees stated healthy lifestyle barriers including lack of time, lack of choices, and lack of safe areas where they could be physically active, as well as general laziness. The lack of time can be caused by lower-income families having to work long hours or more than one job on top of the normal busy schedule of a family. Low physical activity causes great concern due to the number of associated negative health implications (Chatterjee, Blakely, \& Barton, 2005).

In the United States, 300,000 premature deaths per year are linked to obesity and sedentary lifestyles (Gibson, 2003). Unfortunately, sedentary lifestyles are increasing, especially for those who are food insecure. To, Frongillo, Gallegos, and Moore (2014) conducted a study to examine the association between food insecurity and physical activity. The Physical Activity Guidelines for Americans (PAGA) recommended that adults should have a total of at least 150 minutes per week of moderate physical activity, at least 75 minutes per week of vigorous physical activity, or an equivalent of moderate to vigorous physical activity. PAGA recommended that children and adolescents be physically active for at least 60 minutes per day (To, et al, 2014). To, et al (2014) found that food insecure adults were less likely to adhere to PAGA. They also found that food insecure children and adolescence were engaged in less moderate to vigorous physical activity than food secure children; although, they were not less 
likely to adhere to PAGA. The researchers hypothesized that the connection between food insecurity and lower physical activity could be due to two reasons. The first is that food insecurity could lead to nutrient insufficiency, distress, and poor health; therefore, leading to a lesser amount of and intensity of physical activity. The second reason was hypothesized to be that a lesser amount of, and lower intensity of, physical activity could lead to poor general health, higher health costs, and lower work productivity; therefore, causing them to be unable to afford enough food.

Poverty can make providing adequate amounts of food extremely difficult, creating economic, emotional, and mental stress. McCurdy, Gorman, and Metallinos-Katsaras (2010) stated that, "the economic pressure harms parental mental health and increases emotional problems in parents. This leads to less competent and responsive relationships with the child, increasing the likelihood of poor child outcomes” (p. 145). This unhealthy relationship between the child and parent negatively affects the child and how the family runs, ultimately increasing the child's risk of becoming obese. Mental and emotional problems, such as depression, in lowincome mothers have been found to have significant impact on a child being overweight. Depression can lead to less competent parenting such as neglect and disengaged or permissive eating styles (McCurdy, Gorman, \& Metallinos-Katsaras, 2010). These have been found to increase the likelihood of low-income children becoming overweight. They have also shown that depressed mothers are more likely to allow their children to watch a greater amount of television and to allow children to eat while watching television (McCurdy, Gorman, \& Metallinos-Katsaras, 2010). Watching television is associated with obesity because it is a sedentary activity. Eating while watching television leads to over-consumption due to a lack of self-regulation and leads to a higher consumption of energy-dense foods due to food 
advertisements. These factors together lead to an increased chance of obesity (McCurdy, Gorman, \& Metallinos-Katsaras, 2010).

\section{Conclusion}

As stated by Pickett, Kelly, Brunner, Lobstein, and Wilkinson (2005), “where once the rich were fat and the poor were thin, in developed countries these patterns have now reversed" (p. 670). This reversal of roles has led to what is now known as the obesity-hunger paradox. Food insecure individuals struggle to receive adequate nutrition not only due to economic reasons, but to environmental reasons such as residing in food deserts. The Obama Administration's Healthy Food Funding Initiative was a step in the right direction when addressing the issues of food deserts. However, other factors of food insecure food desert residents that are associated with increased BMI have not received enough attention. No national programs are available to improve nutrition for depressed and stressed parents. The same goes for communities who lack safe areas to be physically active or are in need of educating members on healthy lifestyles and nutrition. Although national programs, attention, and funding would be optimal, it is not always feasible. This is where communities, schools, and parents must come together in order to teach and implement strategies so that healthy lifestyles are achieved. Offering nutrition education at a community level may have a major impact in improving nutrition without costing too much (Chatterjee, Blakely, \& Barton, 2005; McCurdy, Gorman, \& Metallinos-Katasaras, 2010).

As the number of food deserts worldwide continues to increase, obesity and its comorbidities such as cardiovascular disease and diabetes will become more prevalent. Obesity is related to a number of negative health implications that cost the country billions of dollars. By 
taking preventative measures and providing proper nutrition for low-income individuals, the country could potentially save money, but more importantly, save lives.

\section{Implications}

In order to address the nutritional needs of food desert residents, officials must understand the relationship between residing in a food desert and diet quality and BMI. Continued research into these topics has the potential to improve understanding of government officials and wellness coalitions. This can lead to the development and implementation of interventions and prevention strategies to improve dietary intake and reduce obesity and other health implications in food desert residents. Strategies would most likely include education on healthy lifestyle behaviors and basic nutrition. Further initiatives and polices are needed in order to address the accessibility and affordability of nutritious foods in food deserts. 


\section{References}

Alviola, P. A., Nayga, R. M., Thomsen, M. R., \& Wang, Z. (2013). Determinants of food deserts. American Journal of Agriculture Economics, 95(5), 1259-1265. doi: 10.1093/ajae/aat029

Baum, C.L. (2011). The effects of food stamps on obesity. Southern Economic Journal, 77(3), 623-651. Retrieved from http://www.jstor.org/stable/40997278

Beydoum, M. A., \& Wang, Y. (2008). How do socio-economic status, perceived economic barriers and nutritional benefits affect quality of dietary intake among US adults? European Journal of Clinical Nutrition, 62(3), 303-313.

Beydoum, M. A., Powell, L. M., \& Wang, Y. (2008). The association of fast food, fruit and vegetable prices with dietary intakes among US adults: Is there modification by family income? Social Science Medicine, 66(11), 2218-2229.

Chatterjee, N., Blakely, D.E., \& Barton, C. (2005). Perspectives on obesity barriers to control from workers at a community center serving low-income Hispanic children and families. Journal of Community Nutrition, 22(1), 23-36. Retrieved from http://www.jstor.org/stable/3427754

Chen, D., Jaenicke, E. C., \& Volpe, R. J. (2016). Food environments and obesity: Household diet expenditure versus food deserts. American Journal of Public Health, 106(5), 881-888. doi 10.21 05/AJPH.201630 3048

Chen, S. E., Florax, R. J. G. M., \& Synder, S. D. (2009). Obesity, fast food, and grocery stores: Evidence from geo-referenced micro data. National Poverty Center Working paper. Retrieved from http://www.npc.umich.edu/news/events/food-access/chen_et_al.pdf 
Chen, Z., Yen. S.T., \& Eastwood, D.B. (2005). Effects of food stamp participation on body weight and obesity. American Journal of Agricultural Economics, 87(5), 1167-1173. Retrieved from http://www.jstor.org/stable/3697691

Clarke, G., Eyre, H., \& Guy, C. (2002). Deriving indicators of access to food retain provision in British cities: Studies of Cardiff, Leeds, and Bradford. Urban Studies, 39(11), 2041-2060.

Coleman-Jensen, A., Rabbitt, M. P., Gregory, C. A., \& Singh, A. (2016). Household food security in the United States in 2015 U.S. Department of Agriculture, Economic Research Service, EER-215. Retrieved from http://www.ers.usda.gov/publications/err-economicresearch-report/err215.aspx

Drewnowski, A., \& Specter, S.E. (2004). Poverty and obesity: The role of energy density and energy costs. American Journal of Clinical Nutrition, 79(1), 6-16. Retrieved from http://ajcn.nutrition.org/content/79/1/6.full.pdf+html

Dutko, P., Ver Ploeg, M., \& Farrigan, T. (2012). Characteristics and influential factors of food deserts. U.S. Department of Agriculture, Economic Research Service, ERR-140. Retrieved from www.ers.usda.gov/publications/err-economic-research-report/err140.aspx

Fan, M. (2010). Do food stamps contribute to obesity in low-income women? Evidence from the National Longitudinal Survey of Youth 1979. American Journal of Agricultural Economics, 92(4), 1165-1180. Retrieved from http://jstor.org/stable/40931073

Gahche, J., \& Sahyoun, N. (2015) Associations between vegetable-and-fruit consumption and food deserts: Urban adults 40+ years, NHANES 2003-2010. The FASEB Journal, 29(1).

Gibson, D. (2003). Food stamp program participation is positively related to obesity in low income women. The Journal of Nutrition, 133(7), 2225-2231. Retrieved from http://jn.nutrition.org/content/133/7/2225.short 
Grimm, K. A., Foltz, J. L., Blanck, H. M., \& Scanlon, K. S. (2012). Household income disparities in fruit and vegetable consumption by state and territory: Results of the 2009 behavioral risk factor surveillance system. The Journal of the Academy of Nutrition and Dietetics, 112(12), 2014-2021.

Guy, C. M., \& David, G. (2004). Measuring physical access to 'healthy foods' in areas of social deprivation: A case study in Cardiff. International Journal of Consumer Studies, 28(3), 222-224.

Hendrickson, D., Smith, C., \& Eikenberry, N. (2006). Fruit and vegetable access in four lowincome food deserts communities in Minnesota. Agriculture and Human Values, 23(3), 471-383.

Hou, S. (2013) Hunger and obesity: Understanding a food insecurity paradigm. Health Promotion Practice, 14(3), 317-320. doi: 10.1177/1524839912475071

Leung, C.W., Ding, E.L., Catalano, P.J., Villamor, E., Rimm, E.B., \& Willett, W.C. (2012). Dietary intake and dietary quality of low-income adults in the supplemental nutrition assistance program. The American Journal of Clinical Nutrition, 96(5), 977-988. Retrieved from http://ajcn.nutrition.org/content/96/5/977.full.pdf+html

Kaur, J., Lamb, M. M., \& Ogden, C. L. (2015). The association between food insecurity and obesity in children-The national health and nutrition examination survey. The Journal of the Academy of Nutrition and Dietetics, 115(5), 751-758.

Kirkpatrick, S. I., Dodd, K. W., Reedy, J., \& Krebs-Smith, S. M. (2012). Income and race/ethnicity are associated with adherence to food-based dietary guidance among U.S. adults and children. The Journal of the Academy of Nutrition and Dietetics, 112(5), 624635. 
McCurdy, K., Gorman, K. S., \& Metallinos-Katsara, E. (2010). From poverty to food insecurity and child overweight: A family stress approach. Child Development Perspectives, 4(2), 144-151. DOI: $10.111 / \mathrm{j} .1750-8606.2010 .00133 . x$

McEntee, J., \& Agyeman, J. (2009) Towards the development of GIS method for identifying rural food deserts: Geographic access in Vermont, USA. Applied Geography, 5(4), 1-12.

Meyerhoefer, C.D., \& Pylypchuk, Y. (2008). Does participation in the food stamp program increase the prevalence of obesity and health care spending? Oxford University Press, 90(2), 287-305. Retrieved from http://www.jstor.org/stable/30139585

Morton, L. W., \& Blanchard, T. C. (2007). Starved for access: Life in rural America’s food deserts. Rural Realities, 1(4), 1-10.

Pickett, K.E., Kelly, S., Brunner, E., Lobstein, T., \& Wilkinson, R.G. (2005). Wider income gaps, wider waistbands? An ecological study of obesity and income inequality. Journal of Epidemiology and Community Health, 59(8), 670-674. Retrieved from http://www.jstor.org/stable/25570806

Rose, D. (1999). Economic determinants and dietary consequences of food insecurity in the United States. Journal of Nutrition, 129, 517S-520S.

To, Q.G., Frongillo, E.A., Gallegos, D., \& Moore, J.B. (2014). Household food insecurity is associated with less physical activity among children and adults in the US population. The Journal of Nutrition, 144(11), 1797-1802. Retrieved from http://www.jstor.org/stable/25653821

United States Department of Agriculture. (2009). Access to affordable and nutritious food: Measuring and understanding food deserts and their consequences. Retrieved from http://www.ers.usda.gov/media/242675/ap036_1_.pdf 
USDA (2016). Fruit and veggies more matters. Retrieved from http://www.fruitsandveggiesmorematters.org/myplate-and-what-is-a-serving-of-fruitsand-vegetables

Whelan, A., Wrigley, N., Warm, D., \& Cannings, E. (2002). Life in a 'food desert.' Urban Studies, 39(11, 18), 2083-2100.

Wrathall, J. (2014). Linking obesity and malnutrition. International Journal of Sociology, 44(2), 63-86. doi: 10.2753/IJS0020-7659440203

Wright, J. D., Donley, A. M., Gualtieri, M. C., \& Strickhouser, S. M. (2016). Food deserts: What is the problem? What is the solution? Society, 53(1) DOI: 10.1007/s12115-016-9993-8

Wrigley, N. Guy, C., \& Lowe, M. (2002). Urban regeneration, social inclusion and large store development: The seacroft development in context. Urban Studies, 39, 2101-2114.

Zenk, S. N., Schulz, A. J., Kannan, S., Lachance, L. L., Mentz, G., Ridella, W. (2012). Neighborhood retail food environment and fruit and vegetable intake in a multiethnic urban population. The American Journal of Health Promotion, 23(4), 255-264. doi: 10.4278/ajhp.071204127. 
APPENDIX A: QUESTIONNAIRE 


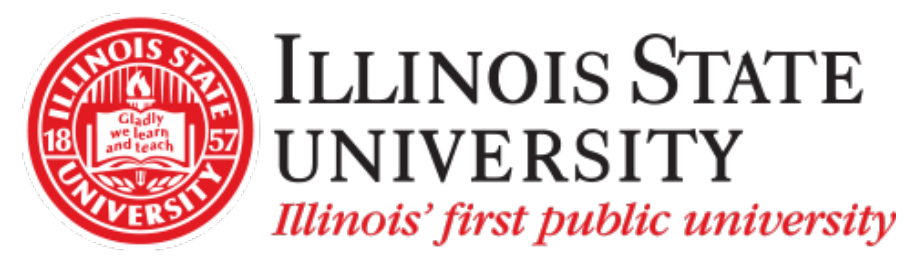

\section{You Are Invited to Participate in a Research Study}

We are interested in having you fill out a questionnaire to understand how fruit and vegetable consumption, diet quality, and body mass index (BMI) are influenced depending on how close you live to a grocery store.

To take part, you must be at least 18 years old and be able to read and understand English. The household member most responsible for grocery shopping should fill out this questionnaire.

If you agree to take participate in this study, please read the informed consent form. This is for you to keep. You will then fill out a questionnaire. This will take no longer than 30 minutes of your time. Please return the filled in questionnaire in the prepaid postage envelope.

If you have questions, please contact Dr. Julie Schumacher at jmraede@ilstu.edu or 309438-7031 or Jamey Baietto at jabaiet@ilstu.edu or (309)-438-7031. 


\section{Consent Form for Participation in a Research Study}

Study Title: Food Desert: Effects on Fruit and Vegetable Consumption, Diet Quality, and BMI Sponsor: Illinois State University

You are invited to participate in a research study to understand how fruit and vegetable consumption, diet quality, and body mass index (BMI) are influenced depending on how close you live to a grocery store.

What are the study procedures? What will I be asked to do?

If you agree to take participate in this study, you will fill out a questionnaire. The questionnaire will take no longer than 30 minutes of your time. You will be asked about yourself and the foods you eat. You can fill out the questionnaire in your home and return it in the prepaid envelope included. We will not be contacting you again after the study.

What are the risks of the study?

We believe there are minimal risks associated with this research study including emotional stress from answering questions related to access to food and body weight. You may stop participation at any time and contact the researchers if you perceive the risks to be a burden.

What are the benefits of the study?

You may not directly benefit from this research; however, we hope that your participation in the study may help us understand how fruit and vegetable consumption, diet quality, and BMI are influenced by how close one lives to a grocery store.

Are there costs to participate?

There are no costs to participate in this study. The envelope for you to return the completed questionnaire is prepaid for your convenience.

How will my personal information be protected?

No names will be associated with the obtained data. Data will be stored in a locked filing cabinet located in the investigator's office in Turner Hall at Illinois State University.

Can I stop being in the study and what are my rights?

Participation is voluntary. There are no penalties or consequences if you do not want to participate or wish to withdraw. Additionally, you do not have to answer any question that you do not want to answer.

Whom do I contact if I have questions about the study?

You may contact the primary investigator, Dr. Julie Schumacher at 309-438-7031 or jmraede@ilstu.edu or the co-investigator, Jamey Baietto at 309-438-7031 or jabaiet@ilstu.edu. If you have any questions concerning your rights as a research participant, you may contact the Illinois State University Research Ethnics and Compliance Office at 309-438-2529 or rec@ilstu.edu.

\section{Documentation of Consent:}

By returning the questionnaire with my responses, I agree to participate. 
Thank you for participating in this research study! The household member most responsible for grocery shopping should complete this packet.

Directions: Fill in the bubble completely indicate your answer. To change your answer, mark an $\mathrm{X}$ on the incorrectly marked answer. Then fill in the correct one. Your answers are important.

1. “The food that I bought just didn't last, and I didn't have money to get more.” Was that often, sometimes, or never true for you or your household in the last 12 months?
O Often true
O Sometimes true
O Never true
O Don’t know

2. "I couldn't afford to eat balanced meals." Was that often, sometimes, or never true for you or your household in the last 12 months?
0 Often true
O Sometimes true
O Never true
O Don't know

3. In the last 12 months, did you or other adults in your household ever cut the size of your meals or skip meals because there wasn't enough money for food?
0 Yes
O No (Skip 4)
O Don’t know (Skip 4)

4. [IF YES ABOVE] How often did this happen—almost every month, some months but not every month, or in only 1 or 2 months?
O Almost every month
O Some months but not every month
O Only 1 or 2 month
O Don't know

5. In the last 12 months, did you ever eat less than you felt you should because there wasn't enough money for food?
O Yes
O No
O Don’t know

6. In the last 12 months, were you every hungry but didn't eat because there wasn't enough money for food?
0 Yes
O No
O Don't know 
7. During the past month, how often did you eat hot or cold cereals?

$\Pi$ Never

$\sqcap 1$ time last month

$\Pi$ 2-3 times last month

$\Pi 1$ time per week

$\sqcap 2$ times per week

$\Pi$ 3-4 times per week

$\Pi$ 5-6 times per week

$\Pi 1$ time per day

$\sqcap 2$ or more times per day

8. During the past month, how often did you have any milk (either to drink or on cereal)? Include regular milks, chocolate, or other flavored milks, lactose-free milk, buttermilk. Please do not include soy milk or small amounts of milk in coffee or tea.

$\Pi$ Never

$\Pi 1$ time last month

$\Pi$ 2-3 times last month

$\Pi 1$ time per week

$\Pi 2$ times per week

$\Pi$ 3-4 times per week

$\Pi$ 5-6 times per week

$\Pi 1$ time per day

$\sqcap$ 2-3 times per day

$\sqcap$ 4-5 times per day

$\sqcap 6$ or more times per day

9. During the past month, what kind of milk did you usually drink?

$\sqcap$ Whole or regular milk

$\Pi 2 \%$ milk

$\Pi 1 \%, 1 / 2 \%$, or low-fat milk

$\Pi$ Fat-free, skim, or nonfat milk

$\Pi$ Soy milk

$\Pi$ Other kind of milk. Print milk. 
10. During the past month, how often did you drink regular soda or pop that contains sugar?

Do not include diet soda.
$\sqcap$ Never
$\Pi 1$ time last month
$\Pi$ 2-3 times last month
$\Pi 1$ time per week
$\Pi 2$ times per week
$\Pi$ 3-4 times per week
$\Pi$ 5-6 times per week
$\Pi 1$ time per day
$\sqcap$ 2-3 times per day
$\sqcap$ 4-5 times per day
$\sqcap 6$ or more times per day

11. During the past month, how often did you drink $\mathbf{1 0 0 \%}$ fruit juices such as orange, mango, apple, grape, and pineapple? Do not include fruit-flavored drinks with added sugar or fruit juice you made at home and added sugar to.

$\Pi$ Never

$\Pi 1$ time last month

$\Pi$ 2-3 times last month

$\Pi 1$ time per month

$\Pi 2$ times per week

$\Pi$ 3-4 times per week

$\Pi$ 5-6 times per week

$\Pi 1$ time per day

$\Pi$ 2-3 times per day

$\sqcap$ 4-5 times per day

$\sqcap 6$ or more times per day

12. During the past month, how often did you drink coffee or tea that had sugar or honey added to it? Include coffee and tea you sweetened yourself and presweetened tea and coffee drinks such as Arizona Iced Tea and Frappuccino. Do not include artificially sweetened coffee or diet tea.

$\Pi$ Never

$\sqcap 1$ time last month

$\Pi$ 2-3 times last month

$\Pi 1$ time per week

$\sqcap 2$ times per week

$\Pi$ 3-4 times per week

$\Pi$ 5-6 times per week

$\Pi 1$ time per day

$\Pi$ 2-3 times per day

$\sqcap$ 4-5 times per day

$\Pi 6$ or more times per day 
13. During the past month, how often did you drink sweetened fruit drinks, sports or energy drinks, such as Kool-Aid, lemonade, Hi-C, cranberry juice, Gatorade, Red Bull, or Vitamin Water? Include fruit juices you made at home and added sugar to. Do not include diet drinks or artificially sweetened drinks.
$\Pi$ Never
$\Pi 1$ time last month
$\Pi$ 2-3 times last month
$\Pi 1$ time per week
$\Pi 2$ times per week
$\Pi$ 3-4 times per week
$\Pi$ 5-6 times per week
$\Pi 1$ time per day
$\sqcap$ 2-3 times per day
$\sqcap$ 4-5 times per day
$\Pi 6$ or more times per day

14. During the past month, how often did you eat fruit? Include fresh, frozen, or canned fruit. Do not include juices.
$\Pi$ Never
$\Pi 1$ time last month
$\Pi$ 2-3 times last month
$\Pi 1$ time per week
$\sqcap 2$ times per week
$\Pi$ 3-4 times per week
$\Pi$ 5-6 times per week
$\Pi 1$ time per day
$\sqcap 2$ or more times per day

15. During the past month, how often did you eat a green leafy or lettuce salad, with or without other vegetables?

$\Pi$ Never

$\Pi 1$ time last month

$\Pi$ 2-3 times last month

$\sqcap 1$ time per week

$\sqcap 2$ times per week

$\Pi$ 3-4 times per week

$\Pi$ 5-6 times per week

$\Pi 1$ time per day

$\Pi 2$ or more times per day 
16. During the past month, how often did you eat any kind of fried potatoes, including French fries, home fries, or hash brown potatoes?
$\sqcap$ Never
$\sqcap 1$ time last month
$\sqcap$ 2-3 times last month
$\prod 1$ time per week
$\sqcap 2$ times per week
$\sqcap$ 3-4 times per week
$\sqcap$ 5-6 times per week
$\Pi 1$ time per day
$\sqcap 2$ or more times per day

17. During the past month, how often did you eat any other kind of potatoes, such as baked, boiled, mashed potatoes, sweet potatoes, or potato salad?
$\sqcap$ Never
$\sqcap 1$ time last month
$\sqcap$ 2-3 times last month
$\sqcap 1$ time per week
$\sqcap 2$ times per week
$\sqcap$ 3-4 times per week
$\sqcap$ 5-6 times per week
$\prod 1$ time per day
$\sqcap 2$ or more times per day

18. During the past month, how often did you eat refried beans, baked beans, beans in soup, pork and beans, or any other type of cooked dried beans? Do not include green beans.

$\sqcap$ Never

$\sqcap 1$ time last month

$\sqcap$ 2-3 times last month

$\prod 1$ time per week

$\sqcap 2$ times per week

$\sqcap$ 3-4 times per week

$\sqcap$ 5-6 times per week

$\sqcap 1$ time per day

$\sqcap 2$ or more times per day 
19. During the past month, how often did you eat brown rice or other cooked whole grains, such as bulgur, cracked wheat, or millet? Do not include white rice.

$\sqcap$ Never

$\sqcap 1$ time last month

$\sqcap$ 2-3 times last month

$\prod 1$ time per week

$\sqcap 2$ times per week

$\sqcap$ 3-4 times per week

$\sqcap$ 5-6 times per week

$\Pi 1$ time per day

$\sqcap 2$ or more times per day

20. During the past month, not including what you just told me about (green salads, potatoes, cooked dried beans), how often did you eat other vegetables?

$\sqcap$ Never

$\sqcap 1$ time last month

$\sqcap$ 2-3 times last month

$\prod 1$ time per week

$\sqcap 2$ times per week

$\sqcap$ 3-4 times per week

$\sqcap$ 5-6 times per week

$\sqcap 1$ time per day

$\prod 2$ or more times per day

21. During the past month, how often did you eat pizza? Include frozen pizza, fast food pizza, and homemade pizza.
$\sqcap$ Never
$\sqcap 1$ time last month
$\sqcap$ 2-3 times last month
$\prod 1$ time per week
$\sqcap 2$ times per week
$\sqcap$ 3-4 times per week
П 5-6 times per day
$\sqcap 1$ time per day
$\sqcap 2$ or more times per day 
22. During the past month, how often did you eat any kind of cheese? Include cheese as a snack, cheese on burgers, sandwiches, and cheese in foods such as lasagna, quesadillas, or casseroles. Do not include cheese on pizza.

$\Pi$ Never

$\Pi 1$ time last month

$\Pi$ 2-3 times last month

$\Pi 1$ time per week

$\sqcap 2$ times per week

$\Pi$ 3-4 times per week

$\Pi$ 5-6 times per week

$\Pi 1$ time per day

$\sqcap 2$ or more times per day

23. During the past month, how often did you eat red meat, such as beef, pork, ham, or sausage? Do not include chicken, turkey, or seafood. Include red meat you had in sandwiches, lasagna, stew, and other mixtures. Red meats may also include veal, lamb, and any lunch meats made with these meats.

$\Pi$ Never

$\Pi 1$ time last month

$\Pi$ 2-3 times last month

$\Pi 1$ time per week

$\Pi 2$ times per week

$\Pi$ 3-4 times per week

$\Pi$ 5-6 times per week

$\Pi 1$ time per day

$\sqcap 2$ or more times per day

24. During the past month, how often did you eat any processed meat, such as bacon, lunch meats, or hot dogs? Include processed meats you had in sandwiches, soups, pizza, casseroles, and other mixtures.

Processed meats are those preserved by smoking, curing, or salting, or by the addition of preservatives. Examples are: ham, bacon, pastrami, salami, sausages, bratwurst, frankfurters, hot dogs, and spam.

$\Pi$ Never

$\sqcap 1$ time last month

$\Pi$ 2-3 times last month

$\Pi 1$ time per week

$\sqcap 2$ times per week

$\Pi$ 3-4 times per week

$\Pi$ 5-6 times per week

$\Pi 1$ time per day

$\sqcap 2$ or more times per day 
25. During the past month, how often did you eat whole grain bread including toast, rolls, and in sandwiches? Whole grain breads include whole wheat, rye, oatmeal, and pumpernickel. Do not include white bread.
$\sqcap$ Never
$\Pi 1$ time last month
$\sqcap$ 2-3 times last month
$\Pi 1$ time per week
$\sqcap 2$ times per week
$\sqcap$ 3-4 times per week
$\sqcap$ 5-6 times per week
$\sqcap 1$ time per day
$\sqcap 2$ or more times per day

26. During the past month, how often did you eat chocolate or any other types of candy? Do not include sugar-free candy.
$\Pi$ Never
$\sqcap 1$ time last month
$\sqcap$ 2-3 times last month
$\sqcap 1$ time per week
$\sqcap 2$ times per week
$\sqcap$ 3-4 times per week
$\sqcap$ 5-6 times per week
$\sqcap 1$ time per day
$\sqcap 2$ or more times per day

27. During the past month, how often did you eat doughnuts, sweet rolls, Danish, muffins, or pop-tarts? Do not include sugar-free items.

$\prod$ Never

$\prod 1$ time last month

$\sqcap$ 2-3 times last month

$\prod 1$ time per week

$\prod 2$ times per week

$\sqcap$ 3-4 times per week

$\sqcap$ 5-6 times per week

$\Pi 1$ time per day

$\sqcap 2$ or more times per day 
28. During the past month, how often did you eat cookies, cake, pie, or brownies? Do not include sugar-free kinds.

$\Pi$ Never

$\Pi 1$ time last month

$\sqcap$ 2-3 times last month

$\Pi 1$ time per week

$\Pi 2$ times per week

$\Pi$ 3-4 times per week

$\Pi$ 5-6 times per week

$\Pi 1$ time per day

$\Pi 2$ or more times per day

29. During the past month, how often did you eat ice cream or other frozen desserts? Do not include sugar-free kinds.
$\Pi$ Never
$\Pi 1$ time last month
$\Pi$ 2-3 times last month
$\Pi 1$ time per week
$\Pi 2$ times per week
$\Pi$ 3-4 times per week
$\Pi$ 5-6 times per week
$\Pi 1$ time per day
$\sqcap 2$ or more times per day

30. During the past month, how often did you eat popcorn?

$\Pi$ Never

$\sqcap 1$ time last month

$\Pi$ 2-3 times last month

$\Pi 1$ time per week

$\Pi 2$ times per week

$\Pi$ 3-4 times per week

$\Pi$ 5-6 times per week

$\Pi 1$ time per day

$\sqcap 2$ or more times per day

31. Are you male or female?
O Male
O Female 
32. What race are you?

O American Indian or Alaska Native

O Asian or Asian American

O Black or African American

O Hispanic

O White

O Other

33. Age

34. Height

35. Weight

36. What is the highest level of school you have completed?

O Have not completed high school

O Received high school diploma or GED

O Some college or technical school

O 4-year degree or more

37. Employment status

O Not employed

O Employed part time

O Employed full time

O Other

38. What is your marital status?

O Married

O Living with partner

O Separated/divorced

O Single, never married

o Other 
39. What is the average yearly income of your household?
0 Less than $\$ 20,000$
O $\$ 20,000-\$ 39,999$
O $\$ 40,0000-\$ 59,999$
O $\$ 60,000-\$ 79,999$
O $\$ 80,000$ or higher

40. What store do you usually shop for groceries at?

41. How do you get to the grocery store?
O On bike or on foot
O A car I own
O Public transportation
0 Other

42. How often do you buy groceries?
O More than once a week
O Once a week
O Once every 2 weeks
0 Once a month or less
O I don't know

Thank you very much for completing this questionnaire! Please return it in the enclosed, prepaid postage envelope. 